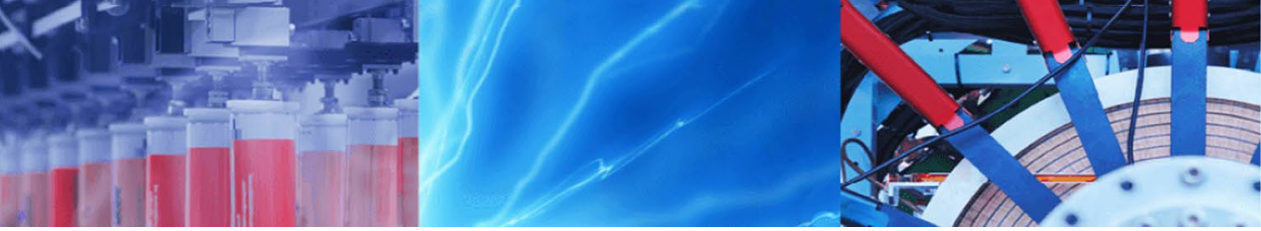

Research Article

\title{
Study on comparative performance of different pavement models incorporated with newly developed jute geotextiles under static loading
}

\author{
Mahuya Ghosh ${ }^{1}$ (1) Guda Venkatappa Rao ${ }^{2,3}$
}

Received: 19 November 2019 / Accepted: 14 March 2020 / Published online: 2 April 2020

(c) Springer Nature Switzerland AG 2020

\begin{abstract}
This research paper describes a laboratory-based unpaved pavement model study incorporating new types of jute geotextiles (JGTs) intended for low-volume roads under static loading. Tests on the pavement models were carried out to evaluate the performance of four types of JGTs, viz. (1) grey (untreated) JGT, (2) rot-proof treated JGT (using reasonably eco-friendly chemicals) and (3) two types of jute-polypropylene (PP) blended geotextiles laid in between a modelled Wet Mix Macadam layer and a suitably compacted subgrade layer. Three types of subgrade soils were used from different geo-climatic regions of the Indian subcontinent including Black Cotton soil. Model tank preparation was done by judiciously selecting some combinations of JGT and subgrade soil based on the outcome of a fundamental study on biodegradability behaviour of these JGTs in the experimental saturated soils. Model tanks were water-treated for different durations up to six months to keep the subgrade soil and the JGT 100\% saturated uninterruptedly before testing to study the effect of time-dependent biodegradability behaviour of the pavement models with and without JGT both. Experimental results clearly indicate that there is a substantial improvement in stress-strain behaviour of the pavement models due to incorporation of any type of the experimental JGTs over control models. The time-dependent model study reveals improvement in stress-strain behaviour of the system in spite of degradation of the JGTs, and jute-PP blended JGT is most effective in improving the pavement models. This indicates that consolidation of subgrade has occurred within a period of 3-6 months.
\end{abstract}

Keywords Jute geotextiles $\cdot$ Rural road $\cdot$ Biodegradability $\cdot$ Pavement model test $\cdot$ Stress-strain behaviour

\section{Introduction}

To improve the connectivity of the rural areas, the Government of India has taken up massive rural road construction activities under the Pradhan Mantri Gram Sadak Yojana (PMGSY) programme since the start of this millennium. This envisages all-weather road access to all villages with population up to 500 and above ( 250 and above for hilly areas). According to Road Development Plan Vision: 2021
[1], other district roads and village roads (low traffic volume roads) come under rural road category.

Expenditure for construction of these roads is increasing every year, especially with poor subgrade soils found abundantly in the Indian subcontinent. According to Indian Road Congress manual IRC: SP-72-2015 [2], soil stabilization is recommended, whenever California Bearing Ratio (CBR) value of the subgrade is less than $5 \%$ to achieve minimum design CBR strength of subgrade to be

$\triangle$ Mahuya Ghosh, mahuya.g@gmail.com | 'Geotech Cell, Indian Jute Industries' Research Association (IJIRA), 17 Taratala Road, Kolkata 700088, India. ${ }^{2}$ Ministry of Textiles, Government of India sponsored project, entitled, “Development of Standards for Use of Jute Geotextiles (JGTs) in Rural Roads", IJIRA, Kolkata, India. ${ }^{3}$ Department of Civil Engineering, Indian Institute of Technology Gandhinagar, Gandhinagar 382355, India. 
$5 \%$. In such situations, use of geotextiles might be an alternate and economically viable solution.

Rural roads are mostly constructed using local soils which have high variability with regard to soil geotechnical properties. Despite the designated quality control measures adopted in their construction, these roads often suffer damages when they are constructed over clayey soils. The clayey soils are very susceptible to moisture, and the roads constructed over these soft soils will get damaged during monsoon due to strength loss and poor drainage conditions. In such cases, either an elevated embankment using favourable soils or stabilization of soft subgrade using suitable admixtures such as lime or cement can be advocated, provided the necessary finances could be allocated. For rural roads, the above approaches are unaffordable. Different types of geosynthetics are being widely used in the pavement system globally to improve the load distribution, separation of clayey subgrade soils from granular layers and to facilitate drainage. Later to the development of geosynthetics, natural geotextiles, a category of geosynthetics, have also been produced using jute and coir fibres [3-5]. Jute, a natural eco-friendly fibre, can be effectively used as raw material for the manufacture of geotextiles due to its suitable mechanical and hydraulic properties. It has better mechanical properties in dry state than that of conventional polyester/polypropylene fibres used for geosynthetics. The fibre is reasonably resistant to biodegradation also being composed of $12-14 \%$ lignin [6]. Additionally, it is known to have good adhesion with asphalt and thermally stable which makes this fibre a suitable raw material for asphalt overlay geosynthetic products [7]. India and Bangladesh are the major jute-producing countries in the world. Total jute and allied fibre production in these two countries is about 3.2 million tonnes in 2016-2017 [8]. Hence, use of natural geotextiles made of $100 \%$ jute or suitable jute-blended geotextiles could be an alternate cost-effective and more environment-friendly approach for construction and maintenance of low-volume roads to improve the road network in these countries.

For the present application, jute geotextiles (JGTs) function as a 'separator' to prevent intermixing of the compacted subgrade soil and the granular (aggregate) layer overlying it and thereby prevent unwanted contamination of granular material and loss in bearing capacity of the system. A JGT fabric simultaneously acts as a 'reinforcement' layer to stabilize and protect weak subgrade in road construction owing to its good tensile properties. The high tensile strength and tear resistance make the JGT fabric to act as a support membrane to reduce localized stresses under wheel path by redistributing traffic loads over a wider area of subgrade [3].

In recent past, Indian Jute Industries' Research Association (IJIRA) has developed a woven JGT having mass per unit area of $724 \mathrm{~g} / \mathrm{m}^{2}$ which has been applied at the interface of subgrade and sub-base layers in many road constructions under PMGSY scheme in five states of India. But from these field studies, exact conclusion regarding the effect of JGT on the entire pavement system cannot be drawn. One of the possible reasons is widely varying geo-climatic conditions in those five states. With regard to biodegradability of JGTs, researchers, e.g. Ramaswamy and Aziz [3] and Som and Sahu [9], reported their opinion that the strength and condition of the jute fabric beyond a period of one year after embedment should not be of any concern as by that time the fabric would have already played an important role in providing a self-sustaining subgrade for most types of soils. Under overburden pressure, the weak subgrade becomes stronger with time due to consolidation which is further accelerated by the drainage action of the geotextile fabric along with its separation and reinforcement functions. The studies related to the performance of a biodegradable geotextile inside a pavement structure with time are still inadequate. To this end, efficacy of suitably engineered JGT for asphalt overlay application has been established at laboratory level $[10,11]$. Additionally, hygral treatment for even a 6-month period is found ineffective in damaging the jute-asphalt interface and the encased jute element [7]. Another laboratory-based study reveals that ageing of soil up to 6 months improves the overall performance of reinforced bed (unpaved road model) in spite of reduction in tensile strength of JGT in clayey soil [12]. But, necessity of chemical rot-proof treatment or blending with suitable counterpart to enhance longevity of the jute product and its performance in different types of soil for application over subgrade are still to be systematically investigated. Hence, a research endeavour was made to investigate the mentioned issues based on pavement model tests at laboratory level in the case of low-volume roads. Initially, some new varieties of JGTs, viz. rot-proof treated woven JGT (by employing an eco-friendlier chemical formulation consisting of an antimicrobial and a water-repellent chemical) and two types of jute-polypropylene (PP) blended woven JGTs, were developed and subsequently their biodegradability in different types of saturated soils was investigated [13]. Subsequently, laboratory evaluation of the efficacy of these newly developed JGTs placed at the interface of the subgrade and a modelled Wet Mix Macadam (WMM) layer within pavement models simulating unpaved roads was carried out under both static and cyclic loading conditions. Three widely varying types of soils from different geo-climatic regions of the Indian subcontinent were employed as 'subgrade' in preparation of the pavement models. This paper presents the results of those static loading tests performed on the model pavements having different subgrade soils and reinforced with newly developed 
JGTs along with the grey (untreated) JGT. In addition, a comparison is made with the results where no geotextile (control) and synthetic geotextiles are used.

\section{Experimental materials and methods}

The laboratory-based pavement model study was planned to be conducted in rectangular pavement model tanks each having outer cross-sectional area of $500 \mathrm{~mm} \times 500 \mathrm{~mm}$ and height of $450 \mathrm{~mm}$. This is as per the dimension of the loading platform of the cyclic loading machine (dimension: $950 \mathrm{~mm} \times 500 \mathrm{~mm}$ ) so that the model tank can be properly mounted on the platform.

\subsection{Types of experimental subgrade soils and their characterization}

Three typical soils from different geo-climatic regions were used for preparation of the subgrade layer of the pavement models, viz. Kolkata Alluvial Silty Soil (Soil K01), Guwahati Lateritic Red Soil (Soil G01) and Andhra Pradesh Black Cotton Soil (Soil B01).

The following properties were tested for the experimental subgrade soils and are provided in Table 1:

- Soil classification based on Atterberg's limits according to IS: 2720 (Part 5).

- Grain size distribution in soils following wet sieving method for the part of soil larger than 75 micron IS sieve and hydrometer method for the part of soil passing 75 micron IS sieve according to IS: 2720 (Part 4-1985)-Reaffirmed 2006.

- Maximum dry density (MDD) and optimum moisture content (OMC) from Standard Proctor compaction test according to IS: 2720 (Part 7)-1980-Reaffirmed 2011

- Soaked CBR values for the soils according to IS: 2720 (Part 16)-1987.

\subsection{Types of experimental geotextiles and their characterization}

Four types of JGTs and one type of synthetic geotextile were used for pavement model preparation. The experimental JGTs are: untreated JGT designated as Grey JGT (developed by IJIRA earlier in a project), newly developed rot-proof treated JGT designated as Treated JGT and two types of jute-PP blended JGTs, designated as Blended JGT $B 1$ (jute:PP $=75: 25$ ) and Blended JGT B2 (jute:PP = 60:40) henceforth. Physical and related functional properties of these geotextiles were determined and are provided in Tables 2 and 3. The biodegradability study [13] reveals that Grey JGT biodegrades in the fastest rate in Soil B01 and the slowest in Soil G01 and in a medium rate in Soil K01. Residual tensile strengths of the Grey JGT are $38.20 \% / 23.87 \%$ (machine direction, $\mathrm{MD} /$ cross-machine direction, $\mathrm{CD}$ ), 29.89\%/21.32\% (MD/CD) and 7.17\%/6.86\% (MD/CD) after remaining embedded in saturated Soil G01, Soil K01 and Soil B01 for 6 months, respectively. Hence, JGTs having better longevity have been developed by chemically rotproofing the Grey JGT and by blending jute with polypropylene. It has been experimentally found that Soil B01 has higher microbial population growth capability than the other two soils. Evidently, Blended JGT B2 showed the best performance in Soil B01. Residual strengths of this fabric are $87.35 \% / 95.64 \%(M D / C D)$ in saturated Soil B01 even after 6 months. It is clear from the biodegradability test data that $100 \%$ grey JGT would not work in Soil B01, although the rot-proof treatment has enhanced the life of the JGTs to some degree, but jute-PP blended JGT is most effective in Soil B01. Hence, jute-synthetic blended JGT fabric is suitable for the Black Cotton soil. Based on this study, some subgrade soil-JGT combinations have been chosen for the pavement model tests which are provided below:
Table 1 Properties of subgrade soils used for pavement model preparation

\begin{tabular}{lllll}
\hline SI. No & Soil properties & Guwahati Lateritic Red Soil & Kolkata Alluvial Silty Soil & $\begin{array}{l}\text { Andhra Pradesh } \\
\text { Black Cotton Soil }\end{array}$ \\
\hline 1 & Liquid limit (\%) & 37 & 33 & 66 \\
2 & Plastic limit (\%) & 25 & 23 & 31 \\
3 & Plasticity index & 12 & 10 & 35 \\
4 & Sand (\%) & 69 & 10 & 22 \\
5 & Silt (\%) & 20 & 65 & 19 \\
6 & Clay (\%) & 11 & 25 & 59 \\
7 & Soil classification & SAND silty clayey & SILT clayey sandy & CLAY sandy silty \\
8 & OMC\% & 14.2 & 15.0 & 34.0 \\
9 & MDD (kN/m $\left.{ }^{3}\right)$ & 17.9 & 17.7 & 13.0 \\
10 & Soaked CBR\% & 8.2 & 4.2 & 1.7 \\
\hline
\end{tabular}


Table 2 Properties of experimental JGTs

\begin{tabular}{|c|c|c|c|c|c|}
\hline Test parameters & Test standards & Grey JGT & Treated JGT & Blended JGT B1 & Blended JGT B2 \\
\hline Fabric construction & - & Double warp plain & Double warp plain & Double warp plain & $\begin{array}{l}\text { Double warp twill } \\
(2 / 1)\end{array}$ \\
\hline Jute:PP blend ratio & - & - & - & $75: 25$ & $60: 40$ \\
\hline Mass per unit area $\left(\mathrm{g} / \mathrm{m}^{2}\right)$ & ASTM D5261:2010 & $721[8.3]$ & $750[1.5]$ & $729[5.5]$ & $843[4.6]$ \\
\hline Thickness $(\mathrm{mm})$ at $2 \mathrm{kPa}$ & ASTM D5199:2012 & $1.62[14.7]$ & $1.55[5.6]$ & $1.74[10.2]$ & $1.95[7.6]$ \\
\hline $\begin{array}{l}\text { Wide width tensile } \\
\text { strength }(\mathrm{kN} / \mathrm{m}) \text { : } \\
(\mathrm{MD} \times \mathrm{CD})^{\mathrm{a}}\end{array}$ & ASTM D4595:2011 & $\begin{array}{l}27.2 \times 25.2 \\
{[13.3,12.6]}\end{array}$ & $\begin{array}{l}26.1 \times 25.5 \\
{[2.5,7.2]}\end{array}$ & $\begin{array}{l}31.9 \times 18.7 \\
{[5.4,9.7]}\end{array}$ & $60.8 \times 30.1[1.6,4.4]$ \\
\hline Elongation\%: $(\mathrm{MD} \times \mathrm{CD})^{\mathrm{a}}$ & & $\begin{array}{l}14.1 \times 8.2 \\
{[12.7,8.5]}\end{array}$ & $\begin{array}{l}12.8 \times 10.0 \\
{[8.3,5.1]}\end{array}$ & $\begin{array}{l}31.2 \times 12.5 \\
{[10.5,14.1]}\end{array}$ & $43.6 \times 30.8[1.5,7.6]$ \\
\hline $\begin{array}{l}\text { Strip tensile } \\
\text { strength }(N):(M D \times C D)^{a}\end{array}$ & $\begin{array}{l}\text { ASTM D5035:2011- } \\
\text { Reapproved }\end{array}$ & $\begin{array}{l}1792.7 \times 1618.5 \\
{[3.3,9.7]}\end{array}$ & $\begin{array}{l}1665.8 \times 1643.6 \\
{[3.9,7.8]}\end{array}$ & $\begin{array}{l}1752.7 \times 1035.0 \\
{[14.3,11.8]}\end{array}$ & $\begin{array}{l}3477.4 \times 1648.4 \\
{[2.8,4.3]}\end{array}$ \\
\hline $\begin{array}{l}\text { Elongation\% at break: } \\
\qquad(\mathrm{MD} \times \mathrm{CD})^{\mathrm{a}}\end{array}$ & $\begin{array}{l}\text { 2015-Ravelled strip } \\
\text { test using specimen } \\
\text { width } 50 \mathrm{~mm}\end{array}$ & $\begin{array}{l}15.2 \times 6.4 \\
{[8.5,8.0]}\end{array}$ & $15.3 \times 9.6[16.8,5.4]$ & $\begin{array}{l}22.3 \times 6.4 \\
{[16.6,7.0]}\end{array}$ & $\begin{array}{l}31.7 \times 24.1 \\
{[5.3,12.5]}\end{array}$ \\
\hline $\begin{array}{l}\text { Trapezoidal tear strength } \\
(\mathrm{N}) \\
(\mathrm{MD} \times \mathrm{CD})^{\mathrm{a}}\end{array}$ & ASTM D4533:2015 & $\begin{array}{l}275.9 \times 256.2 \\
{[10.7,17.5]}\end{array}$ & $\begin{array}{l}301.1 \times 290.9 \\
{[9.5,13.0]}\end{array}$ & $\begin{array}{l}771.4 \times 298.5 \\
{[14.3,9.7]}\end{array}$ & $\begin{array}{l}1235.6 \times 580.9 \\
{[4.4,10.4]}\end{array}$ \\
\hline $\begin{array}{l}\text { Apparent opening size } \\
\text { (micron) }\end{array}$ & ASTM D4751:2016 & 130 & 225 & 407 & 230 \\
\hline $\begin{array}{l}\text { Static puncture strength } \\
(\mathrm{kN})\end{array}$ & ASTM D6241:2014 & $2.9[16.4]$ & $3.2[13.1]$ & $3.3[12.7]$ & $5.4[4.5]$ \\
\hline Permittivity $\left(\mathrm{s}^{-1}\right)$ & ASTM D4491:2017 & $0.23[9.5]$ & $0.31[19.8]$ & $0.44[13.7]$ & $0.19[11.8]$ \\
\hline
\end{tabular}

Numbers shown within parenthesis are values of co-efficient of variation percentages (C.V.\%) for the test parameters ${ }^{\mathrm{a}} \mathrm{MD} \times \mathrm{CD}$ : machine direction $\times$ cross-machine direction

Table 3. Properties of experimental synthetic geotextile

\begin{tabular}{lll}
\hline Property & Test standards & Mean (C.V.\%) \\
\hline Fabric construction and type & - & Polypropylene Nonwoven fabric \\
Mass per unit area $\left(\mathrm{g} / \mathrm{m}^{2}\right)$ & ASTM D5261:2010 & $279.0[9.8]$ \\
Thickness at $2 \mathrm{kPa}(\mathrm{mm})$ & ASTM D5199:2012 & $1.77[7.9]$ \\
Wide width tensile strength $(\mathrm{kN} / \mathrm{m}):(\mathrm{MD} \times \mathrm{CD})^{\mathrm{a}}$ & ASTM D4595:2011 & $18.5 \times 19.6[5.2,4.4]$ \\
Wide width extension\%: $(\mathrm{MD} \times \mathrm{CD})^{\mathrm{a}}$ & ASTM D4595:2011 & $56.2 \times 48.2[5.4,7.9]$ \\
Strip tensile strength $(\mathrm{N}):(\mathrm{MD} \times \mathrm{CD})^{\mathrm{a}}$ & ASTM D5035:2011-Reapproved 2015-Rav- & $890.4 \times 979.4[6.4,4.9]$ \\
& elled strip test using specimen width & \\
Strip elongation\% at break: $(\mathrm{MD} \times \mathrm{CD})^{\mathrm{a}}$ & 50 mm & $52.6 \times 65.3[4.7,8.6]$ \\
& ASTM D5035:2011-Reapproved 2015-Rav- & \\
Apparent opening size $(\mathrm{micron})$ & elled strip test using specimen width & 66 \\
Static puncture strength $(\mathrm{N})$ & 50 mm & $2825.3[5.7]$ \\
Trapezoidal tear strength $(\mathrm{N}):(\mathrm{MD} \times \mathrm{CD})^{\mathrm{a}}$ & ASTM D4751:2016 & $251.5 \times 356.8[2.6,12.3]$ \\
Permittivity $\left(\mathrm{s}^{-1}\right)$ & ASTM D6241:2014 & $0.88[18.4]$ \\
\hline
\end{tabular}

Numbers shown within parenthesis are values of co-efficient of variation percentages (C.V.\%) for the test parameters

${ }^{a} \mathrm{MD} \times \mathrm{CD}$ : machine direction $\times$ cross-machine direction

Guwahati Red Lateritic Soil (Soil G01): Grey JGT, Treated JGT.

Kolkata Alluvial Silty Soil (Soil K01): Treated JGT, Blended JGT B1.
Andhra Pradesh Black Cotton Soil (Soil B01): Blended JGT B1, Blended JGT B2, Synthetic GT. 


\subsection{Selection of modelled Wet Mix Macadam (WMM) mix composition}

A modelled WMM composition (provided in Table 4) was judiciously selected instead of actual WMM Grading 1 (IRC: 109-1997) [14] to prepare the main load bearing layer of the pavement model. Modified WMM grading was so chosen to accommodate with the cross-sectional area of the model tank, i.e. $500 \mathrm{~mm} \times 500 \mathrm{~mm}$.

\subsection{Preparation of the pavement model tanks}

Two types of rectangular tanks with water inlet valve at the bottom were fabricated for this study, viz. (a) transparent plastic tanks (made of $11 \mathrm{~mm}$ thick acrylic plates fitted inside a rigid aluminium frame which is further secured by long mild steel nut-bolt sets at three vertically different positions) for hand compaction of subgrade layers to create a very soft subgrade having CBR at tank density below 2 and (b) metallic tanks (made of $2.5 \mathrm{~mm}$ thick stainlesssteel plates fitted along the outer edges and the middleheight boundary with mild steel angles) for mechanical compaction of subgrade layers. The consecutive steps for preparation of pavement models of different composition in tanks are described below:

1. Dry soil of desired quantity was mixed thoroughly with required amount of water (either OMC amount or to prepare a subgrade having CBR below 2 depending on the type of soil).

2. The wet soil in suitably wrapped condition was kept for $24 \mathrm{~h}$ to get a homogeneous mix. Soil B01 being a swelling soil, it was kept for $48 \mathrm{~h}$ for proper water penetration inside the bulk of the soil mass.

3. A layer of medium-grained sand was laid at the base of the tank just below the level of water inlet valve.

4. All the four side walls and the bottom of the tank were covered with filter paper properly to provide a passage for water to get drained out up to the tank bottom. Inner walls of the metallic tank were covered with thin perspex sheet (thickness: $2 \mathrm{~mm}$ ) to create almost frictionless boundary walls.
5. Subgrade layer of $300 \mathrm{~mm}$ design thickness was prepared by compacting six layers of wet soil successively from bottom to top each having a compacted thickness of $50 \mathrm{~mm}$. To do this, homogenized wet soil for each layer was weighed separately and subsequently poured into the tank followed by application of desired compaction effort. To keep initial CBR value of subgrade layer of the pavement models below 2, compaction effort applied was different for each type of subgrade soil. The moisture content and compaction effort details for preparation of the subgrade layers of the pavement models are provided below:

(a) Subgrade layer of Soil K01: 20\% moisture content (i.e. nearly at plastic limit of the soil); each of the six layers was hand-compacted. To keep the density of the hand-compacted subgrades nearly similar for all the tanks containing Soil K01, same person had compacted all those tanks by applying pressure using his fist. In this manner, dry density obtained in tank is $70 \%$ of the soil's MDD. CBR of this soil at tank density is $1.2 \%$.

(b) Subgrade layer of Soil G01:Two types of models were prepared using this soil. For both the types, $14 \%$ moisture content (i.e. at OMC) was kept; but the six layers were mechanically compacted using a suitable rammer applying dissimilar number of blows to achieve at two different dry densities, viz. $74 \%$ and $100 \%$ of the soil's MDD. CBR of this soil at tank density of $74 \%$ MDD is $0.9 \%$.

(c) Subgrade layer of Soil B01: 34\% moisture content (i.e. at $\mathrm{OMC}$ ); six layers were mechanically compacted using a suitable rammer to achieve a dry density of $100 \%$ of the soil's MDD.

6. For geotextile-embedded tanks, after preparation of subgrade of $300 \mathrm{~mm}$ thickness, the geotextile of suitable size securely mounted in a rectangular aluminium anchoring frame in unfolded taut condition was placed over the subgrade.
Table 4. Composition of modelled WMM mix

\begin{tabular}{lll}
\hline IS sieve designation & $\begin{array}{l}\text { Percentage passing by weight for WMM } \\
\text { as per IRC: 109-1997 }\end{array}$ & $\begin{array}{l}\text { Percentage passing by } \\
\text { weight of the modelled } \\
\text { WMM mix }\end{array}$ \\
\hline $14 \mathrm{~mm}$ & 100 (Assumed) & 100 \\
$11.20 \mathrm{~mm}$ & $40-60$ & 49.72 \\
$4.75 \mathrm{~mm}$ & $25-40$ & 31.94 \\
$2.36 \mathrm{~mm}$ & $15-30$ & 19.24 \\
$600 \mathrm{micron}$ & $8-22$ & 10.73 \\
75 micron & $0-5$ & 5.23 \\
\hline
\end{tabular}


7. Modelled WMM mix of desired quantity was thoroughly mixed with water at OMC of the mix.

8. The wet mix was laid either on top of JGT or directly over subgrade (for control model) and subsequently levelled up to the layer thickness of $75 \mathrm{~mm}$ by applying very mild compaction effort to achieve a dry density of $17.95 \mathrm{kN} / \mathrm{m}^{3}$ which was $82.68 \%$ of MDD of the mix. This was done to avoid penetration of the WMM layer inside soft subgrade layer beneath.

9. A lightweight plastic sheet was kept over the prepared WMM layer to place the surcharge loads and uniformly distribute the loads over the cross-sectional area of the tank.

10. Surcharge loads were placed on the mentioned sheet to provide the total design pavement load over the compacted subgrade along with the WMM layer. Desired surcharge loads were calculated as per IRC:72-2015 for cumulative ESAL (Equivalent Standard Axle Load) repetitions 30,000-60,000 for 10 years and subgrade CBR of 2 .

11. All model tanks were then supplied continuously with sufficient water from bottom through the inlet valve for one week so that the subgrade became nearly $100 \%$ saturated.

12. After one week, the model tanks were kept further under surcharge loads for different durations, e.g. zero week, 4 weeks, 12 weeks and 24 weeks, maintaining the subgrade soil $100 \%$ saturated by watering them continuously. This exercise was undertaken to investigate deterioration of JGT with time within completely saturated pavement and its effect on the performance of the entire pavement. Water treatment of the pavement models for 24 weeks would provide the effect of two monsoons considering 12 weeks for each monsoon.

13. After desired time period, the water-treated model tanks were ready for static loading test.

Three different types of pavement models were prepared. These were:

(a) Pavement models having only compacted subgrade layer of $300 \mathrm{~mm}$ thickness which simulate a mud road without any pavement. These models were watertreated without any surcharge loads.

(b) Control pavement models having compacted subgrade layer of $300 \mathrm{~mm}$ thickness and modelled WMM layer of $75 \mathrm{~mm}$ thickness; these simulate conventional unpaved roads

(c) JGT/geotextile-embedded pavement models having compacted subgrade layer of $300 \mathrm{~mm}$ thickness, modelled WMM layer of $75 \mathrm{~mm}$ thickness and a geotextile at the interface of the two layers which simulate geotextile-embedded unpaved roads.

In Fig. 1, the cross-section of a pavement model tank is shown.

\subsection{Static loading test}

To determine the complete stress-strain behaviour of the pavement models, static loading tests were carried out. After removing surcharge loads, the tank was placed on the loading platform of the cyclic loading machine. The dimension of the loading plate was selected to be $150 \mathrm{~mm}$ considering the linear dimension of the test area (i.e.
Fig. 1 Schematic cross-sectional view of pavement model

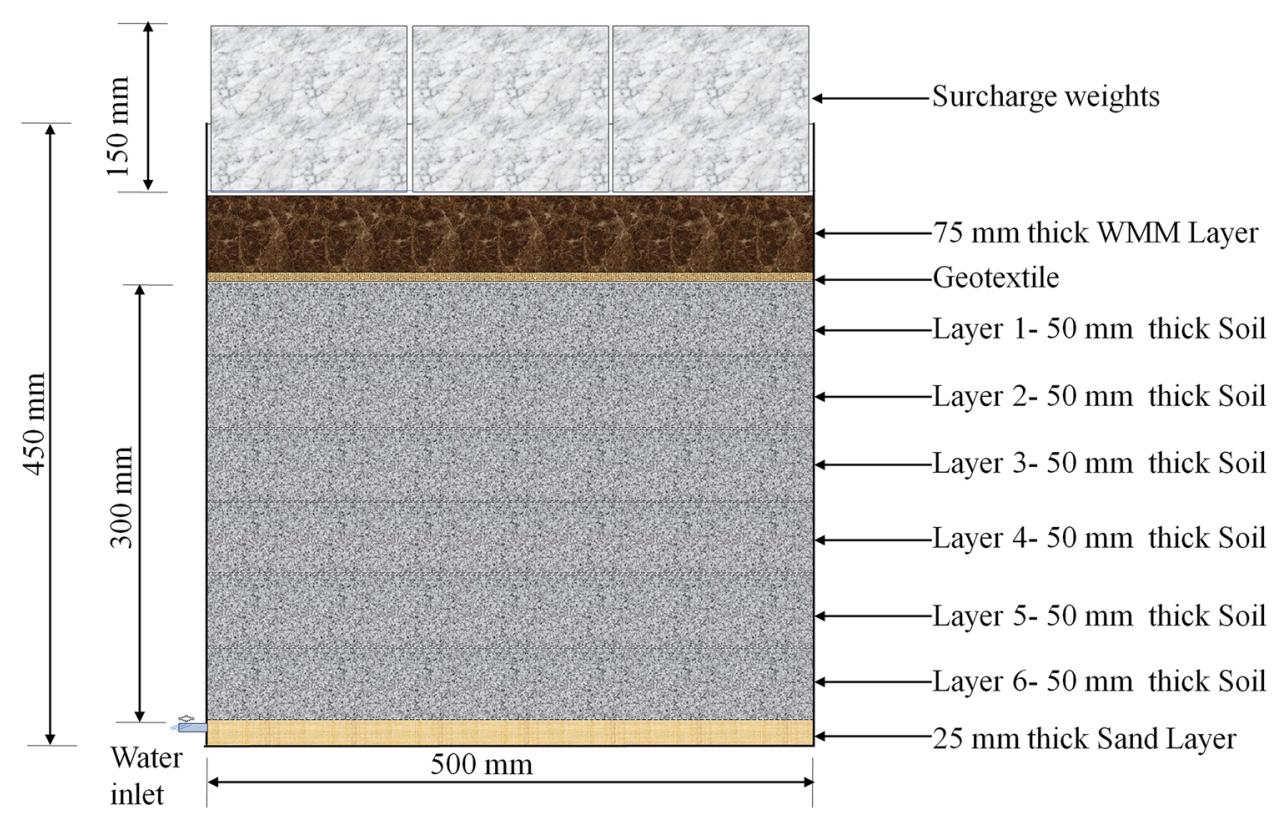


$500 \mathrm{~mm}$ ) and the nominal size of the larger aggregates ( $\approx 14 \mathrm{~mm}$ ) of the modelled WMM. Now, the models were subjected to static loading through this loading plate at a deformation rate of $0.05 \mathrm{~mm} / \mathrm{s}$ for undrained condition. The actual test arrangement is shown in Fig. 2.

For each tank, degree of saturation and dry densities of the compacted subgrade were determined after conducting the static loading test.

\section{Results and discussion}

\subsection{Properties of experimental soils}

The properties of three types of experimental subgrade soils are provided in Table 1. Soil classification study reveals that Soil G01 is basically a plastic sand, Soil K01 is mostly a silt and Soil B01 is a swelling clay. Hence, the three soils are widely different from each other with respect to their geotechnical behaviour and are representing the majority of the Indian subcontinent soils.

\subsection{Properties of experimental JGT fabrics}

The properties of Grey JGT and newly developed rotproof treated and jute-PP blended JGTs are reported in Table 2. From the table, it is observed that for development

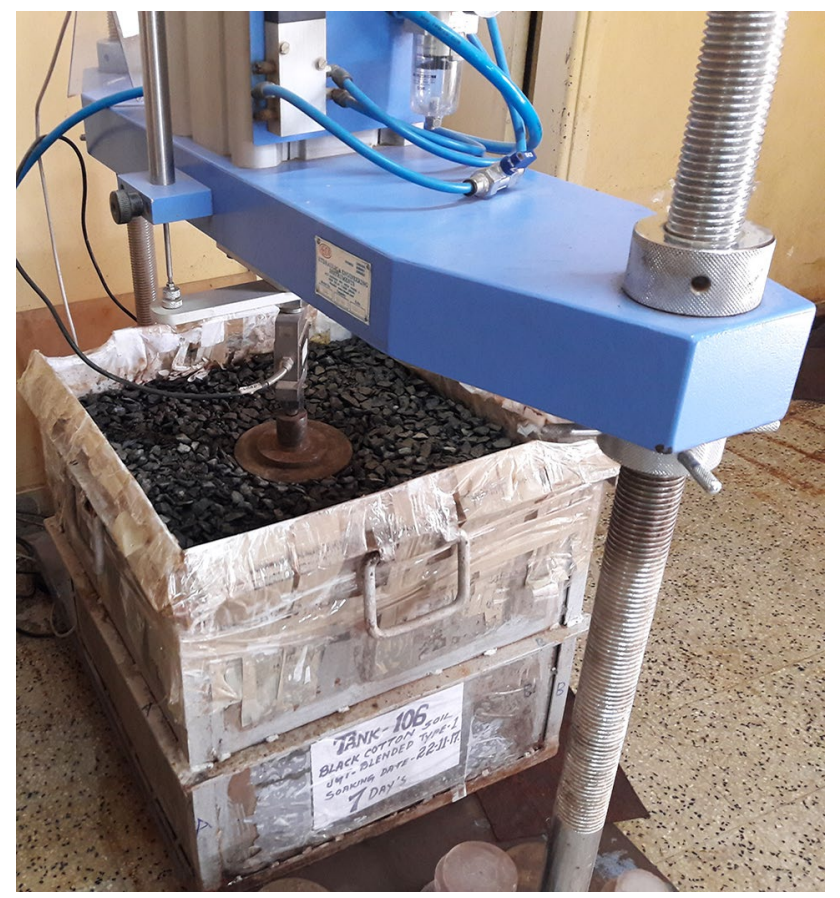

Fig. 2 Pavement model test in progress using cyclic loading machine of blended JGTs, if proportion of PP is increased, then tensile strength (both Strip and Wide width) of the fabric increases. However, there is the simultaneous increase in considerable amount of extensibility of the product which is undesirable for this application. For the present end-use, moderate extensibility of the geotextile product is desirable. The developed jute-PP blended products will reinforce the unpaved roads through tensioned membrane support due to their high extensibility feature.

At this juncture, it is noteworthy to mention that jute-PP blended geotextiles have been developed to substantially enhance the longevity of the product in problematic soils, like Soil B01 where chemical rot-proofing of Grey JGT has been found unsatisfactory [13]. One objective of the present study is to reduce the carbon footprint by reducing the quantity of synthetic materials/fibres and introducing a mechanically robust natural fibre jute for manufacturing geotextiles, whereas $100 \%$ synthetic geotextile products are being used all over the world in different road construction projects.

If a comparison can be made among all the experimental JGTs vis-à-vis the synthetic geotextile (used in model pavement study; Table 3), then the following general observations can be made:

(a) JGTs are heavier than the synthetic geotextile

(b) Experimental JGTs are woven, and the synthetic geotextile is nonwoven

(c) In general, the synthetic geotextile (Synthetic GT) is weaker fabric than the experimental JGTs, but the former is having much higher extensibility than the experimental JGTs. The cross-directional strength of Blended JGT B1 is comparable with this geotextile only.

\subsection{Modelled WMM layer}

Selected modelled WMM (Table 4) was laid in the tank by light compaction to avoid intrusion of WMM inside subgrade or puncturing of geotextile at the interface. Hence, MDD of the modelled WMM could not be achieved. Dry density of modelled WMM achieved in tank is $17.95 \mathrm{kN} /$ $\mathrm{m}^{3}$, whereas MDD of the modelled WMM is $21.71 \mathrm{kN} / \mathrm{m}^{3}$. Hence, $82.68 \%$ of MDD has been achieved in tank. The CBR of the modelled WMM as compacted in tank is $35.78 \%$ of the actual CBR of the selected WMM mix. 


\subsection{Static test results for the pavement models}

\subsubsection{Static test results for the pavement models having Soil G01 as subgrade soil}

In Fig. 3, the vertical stress versus per cent strain behaviour of control test models consisting of Soil G01 as subgrade soil and compacted at 74\% MDD for curing periods up to 24 weeks and also results of the subgrade-only model cured for zero week (i.e. 7 days water-treated for achieving nearly $100 \%$ saturation level) are depicted. The values of subgrade soil dry density $\left(\gamma_{d}\right)$ for subgrade-only model, control models with no curing, 4-week curing, 12-week curing and 24-week curing, are determined to be 14.80 $\mathrm{kN} / \mathrm{m}^{3}, 14.97 \mathrm{kN} / \mathrm{m}^{3}, 15.02 \mathrm{kN} / \mathrm{m}^{3}, 15.98 \mathrm{kN} / \mathrm{m}^{3}$ and 16.00 $\mathrm{kN} / \mathrm{m}^{3}$, respectively. It is to be noted that the density of the subgrade layer is found to improve with curing time as expected. From these curves, it is observed that the control model cured for 24 weeks exhibits the best behaviour which depicts the stresses at $10 \%$ strain and $30 \%$ strain being $80 \mathrm{kPa}$ and nearly $116 \mathrm{kPa}$, respectively, vis-à-vis the corresponding stresses at the same strain levels for control model with no curing being $52 \mathrm{kPa}$ and $76 \mathrm{kPa}$, respectively.

Figure 4 presents the behaviour of the pavement models embedded with Grey JGT having subgrade Soil G01
Fig. 3 Vertical stress versus per cent strain plots for control and subgrade-only pavement models having Soil G01 as subgrade soil compacted at $74 \%$ MDD
Fig. 4 Vertical stress versus per cent strain plots for Grey JGTembedded pavement models having Soil G01 as subgrade soil, compacted at 74\% MDD

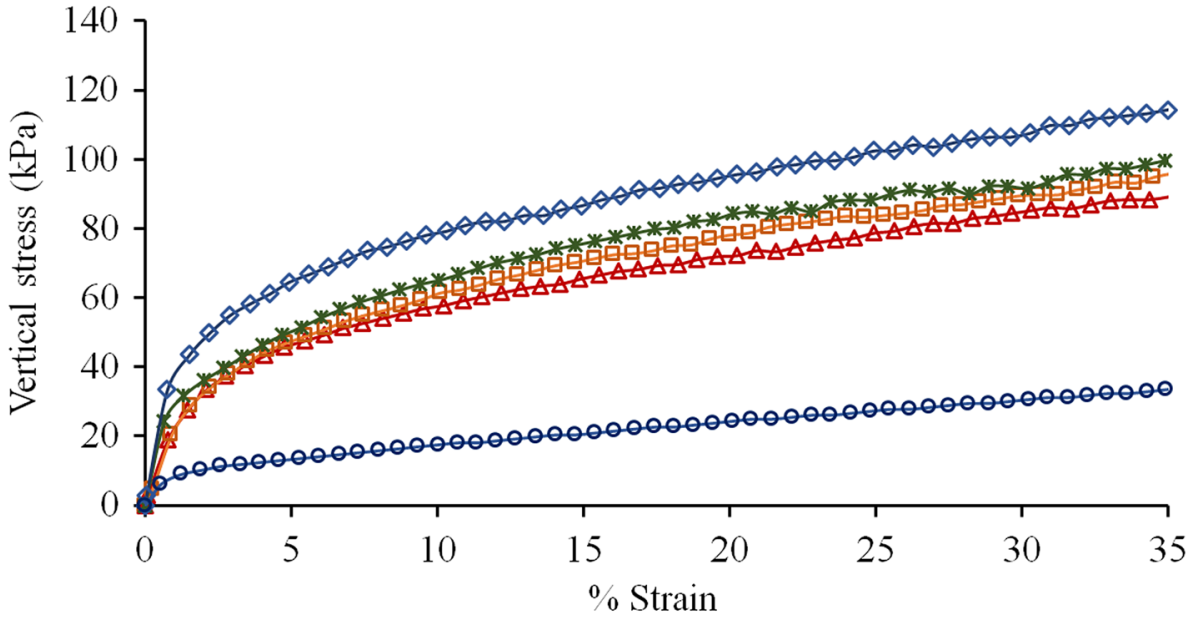

$\triangle$ Soil G01_Control_zero week $\quad$ Soil G01_Control_4 week *Soil G01_Control_12 week $\rightarrow$ Soil G01_Control_24 week

๑Soil G01_Only subgrade_zero week

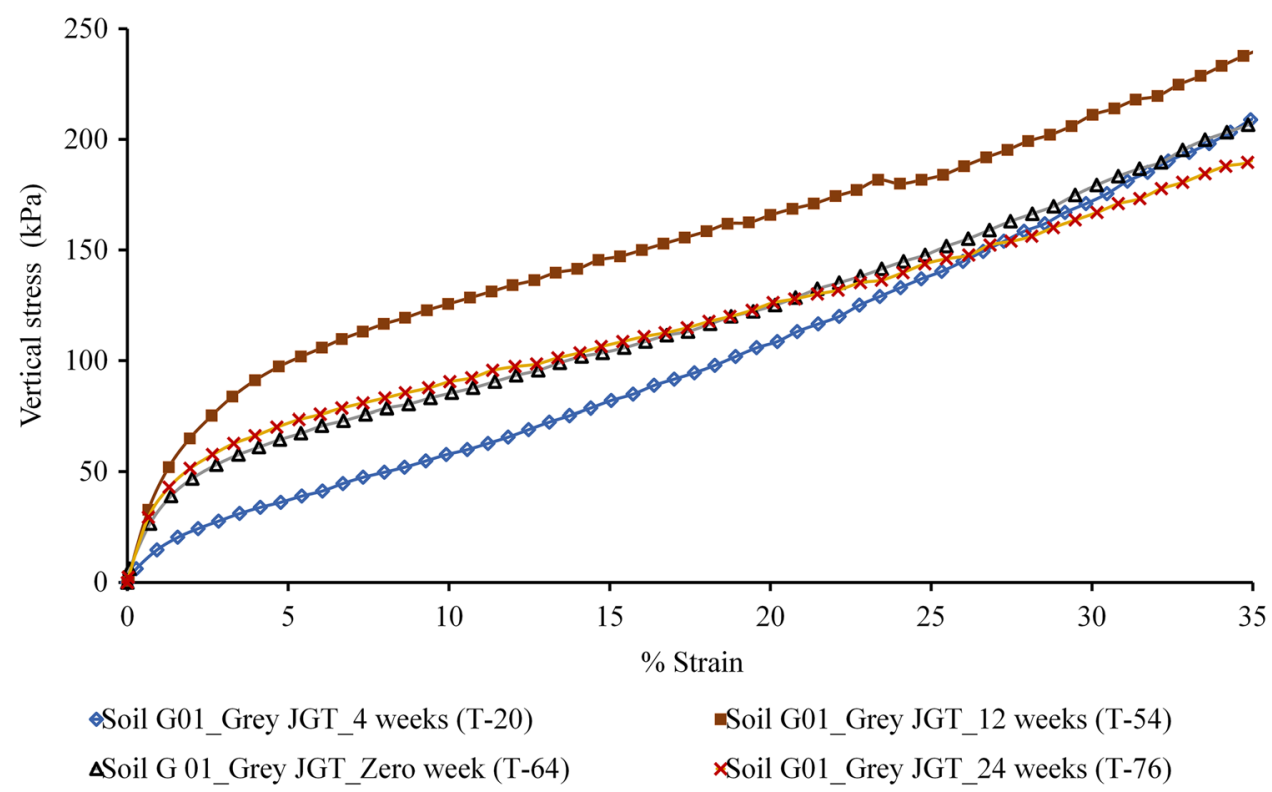


compacted at $74 \%$ MDD and the associated tanks cured up to 24 weeks. The vertical stress versus per cent strain curve for 24-week cured pavement model is observed to be lower than the 12-week one possibly due to the higher level of biodegradation of the JGT as the dry densities of subgrade soils are same for the two tanks, i.e. 15.22 $\mathrm{kN} / \mathrm{m}^{3}$. The biodegradability study [13] reveals that the residual strengths in Grey JGT in saturated Soil G01 after 3 months are $66.4 \%$ in warp-way (MD) and $55.7 \%$ weftway (CD), respectively, and those for the same JGT embedded in the same soil after 6 months are $34.5 \%$ and $23.0 \%$, respectively. The curve for 4-week curing is lower than that of zero-week curing owing to the lower density of the 4-week cured tank $\left(14.48 \mathrm{kN} / \mathrm{m}^{3}\right)$ in comparison with the zero-week tank $\left(15.62 \mathrm{kN} / \mathrm{m}^{3}\right)$. The profile for 24 -week cured model almost follows zero-week curve up to $21 \%$ strain level and thereafter falls below the latter to some extent. In spite of enormous geotextile degradation (about $70 \%$ strength loss) and lower subgrade density (i.e. 15.22 $\mathrm{kN} / \mathrm{m}^{3}$ ) in 24-week model, the pavement model performs almost at par with the zero-week model.

It is observed in general that the influence of JGT is hardly seen up to the strain level of $10 \%$, but at higher strain levels, it is evident.

Figure 5 presents vertical stress-strain (\%) behaviour of Treated JGT-embedded pavement models cured for different durations up to 24 weeks. The stress-strain profile of the 12-week cured model falls below that of the 4-week model beyond 15\% strain level. The profile for 24-week cured model almost follows zero-week curve. This is possibly due to the higher level of fabric degradation in 12-week and 24-week cured models than that of 4-week model. The zero-week tank is showing the lowest stress-strain curve among the three models embedded with Treated JGT. The tank subgrade density values for the pavement models cured for zero-week, 4-week, 12-week and 24-week are nearly the same: $15.34 \mathrm{kN} / \mathrm{m}^{3}, 15.37 \mathrm{kN} /$ $\mathrm{m}^{3}, 15.43 \mathrm{kN} / \mathrm{m}^{3}$ and $15.42 \mathrm{kN} / \mathrm{m}^{3}$, respectively. It can be also observed that Grey JGT- and Treated JGT-embedded models produce higher stress-strain curves than all the control models even after considerable biodegradation of JGT fabrics in 24 weeks.

In Fig. 6, vertical stress versus per cent strain profiles for the control and Grey JGT-embedded pavement models having subgrades compacted at MDD are plotted. The model tanks were cured from zero week up to 12 weeks. Evidently, both the control and Grey JGT reinforced models are showing higher stress-strain profiles than those for which subgrade densities are lower, i.e. subgrades compacted at 74\% of MDD (Figs. 3 and 4). The effect of JGT can be found beyond $10 \%$ strain level increasing significantly thereafter. Effect of consolidation of subgrade soil is clear from the 12-week curves as they are showing the highest positions for both the control and the reinforced models;

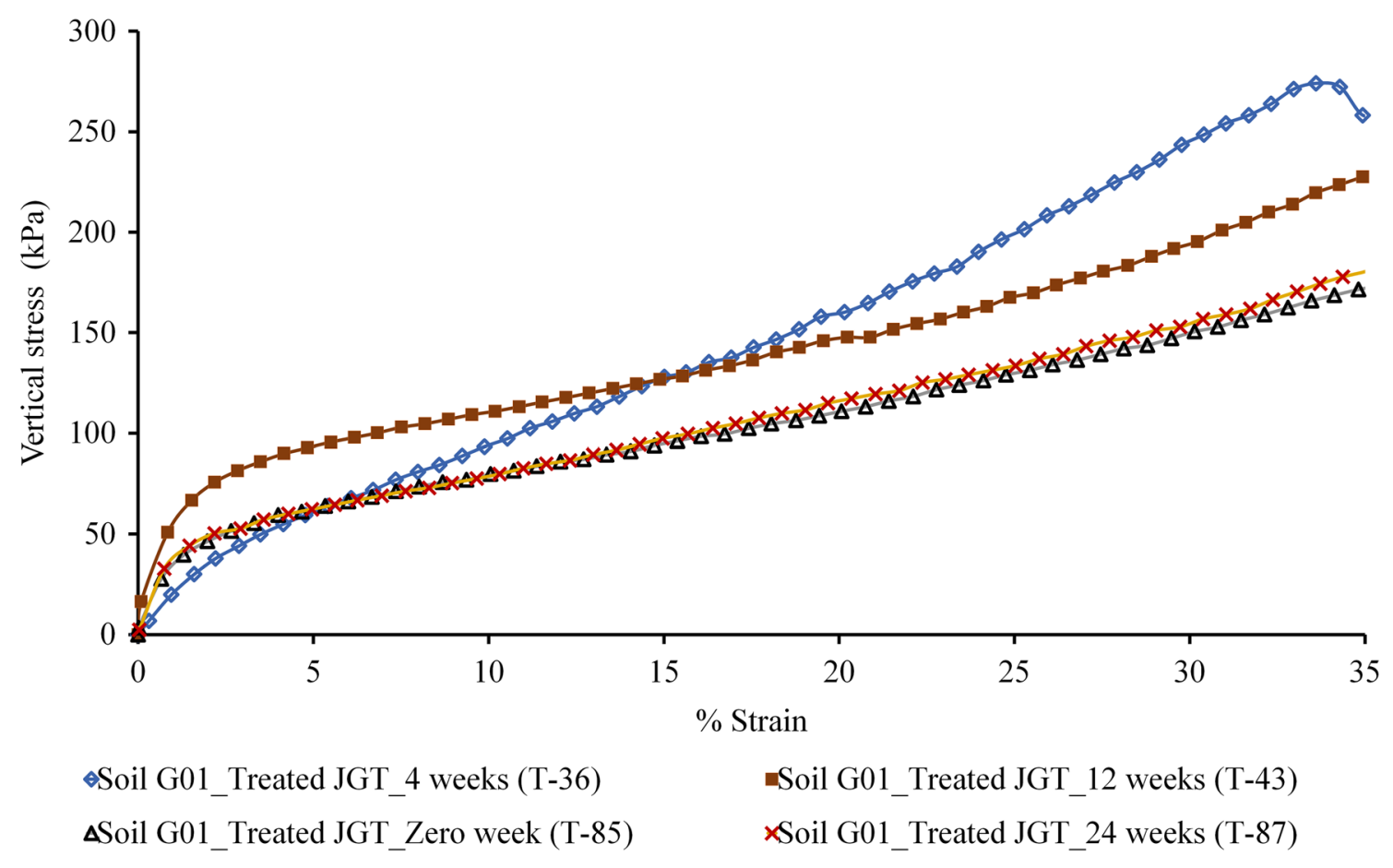

Fig. 5 Vertical stress versus per cent strain plots for Treated JGT-embedded pavement models having Soil G01 as subgrade soil, compacted at $74 \%$ MDD 
Fig. 6 Vertical stress versus per cent strain plots for the control and Grey JGT-embedded pavement models having Soil G01 as subgrade compacted at $100 \%$ MDD

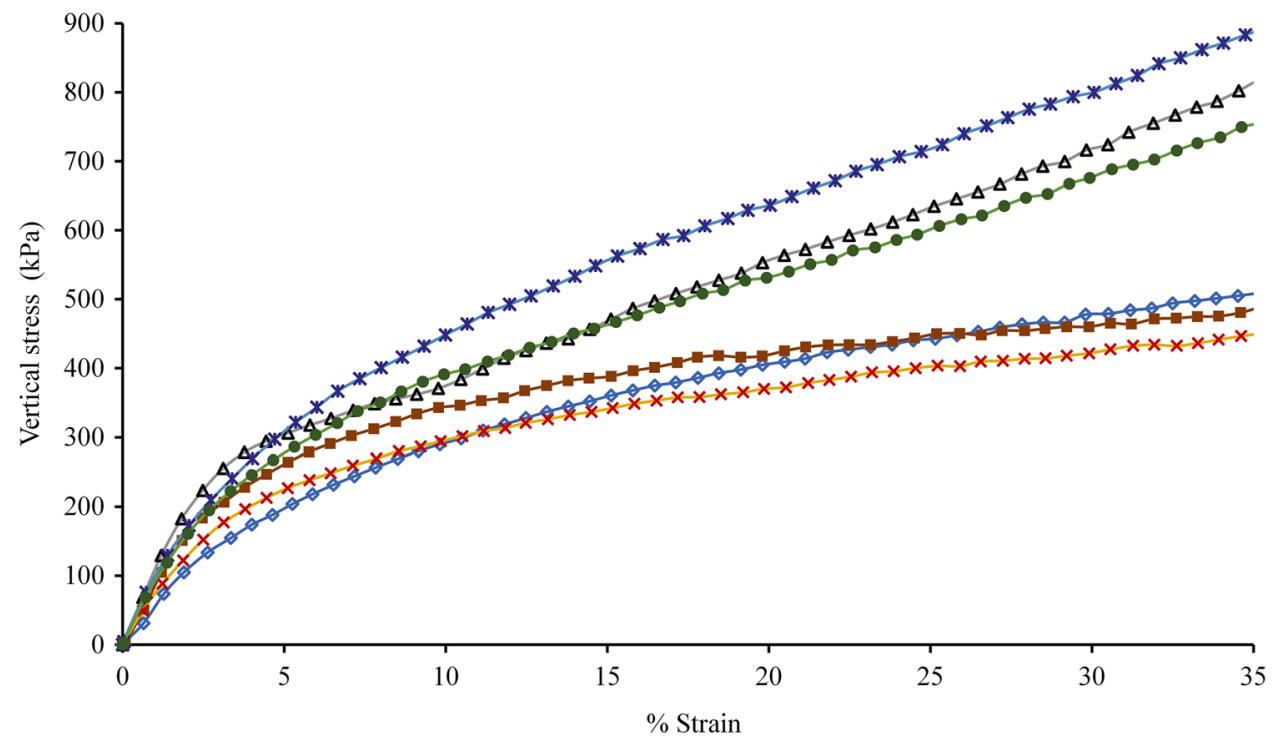

थSoil G01 (MDD) Control 12 weeks (T-97) $\Delta$ Soil G01(MDD)_Grey JGT_Zero week (T-104) *Soil G01 (MDD)_Grey JGT_12 weeks (T-110)
-Soil G 01 (MDD) Control Zero week (T-102) ×Soil G01 (MDD)_Control_4 weeks (T-107) -Soil G01(MDD)_Grey JGT_4 weeks (T-128) especially, it is very prominent in the reinforced model. In spite of the decomposition of the JGT, the subgrade becomes stronger due to consolidation.

In the cases of zero-week cured models for subgrade layers compacted at $74 \%$ of MDD and $100 \%$ MDD, advantage of JGT reinforcement over the control is more for the former than the latter. This fact is more prominent at the higher strain levels. Hence, it can be concluded that immediate road construction work can be started employing a suitable JGT as 'separator-cum-reinforcement' layer over soft subgrade. This effect gradually reduces with time as the soil itself becomes stronger due to consolidation and the JGT biodegrades. Hence, JGT is helping in rapid construction of roads like other synthetic geotextiles as also reported by Pancar and Akpınar [15].

\subsubsection{Static test results for the pavement models having Soil $\mathrm{K} 01$ as subgrade soil}

Referring to Figs. 7, 8 and 9, which present the vertical stress versus per cent strain behaviour of control models and Blended JGT B1- and Treated JGT-embedded models
Fig. 7 Vertical stress versus per cent strain plots for control and subgrade-only pavement models having Soil K01 as subgrade soil compacted at 70\% MDD

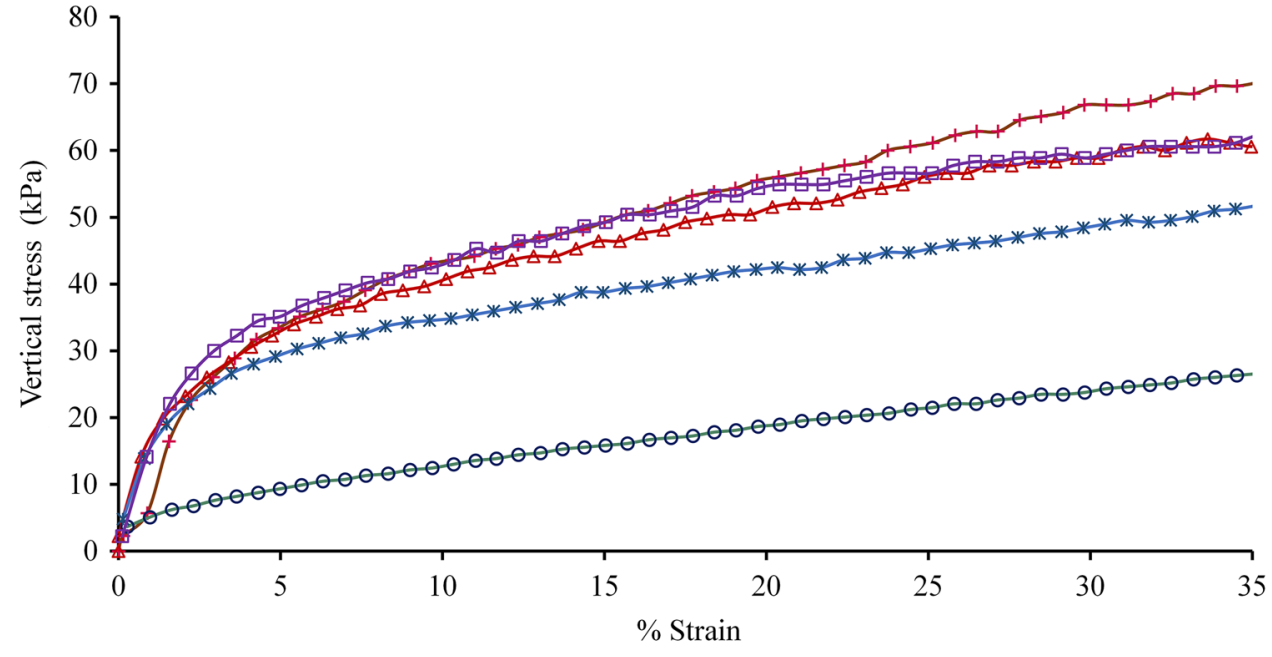

+Soil K 01_Control_4 weeks OSoil K01_Only subgrade_Zero week ASoil K 01_Control_12 weeks *Soil K01_Control_Zero week 
Fig. 8 Vertical stress versus per cent strain plots for Blended JGT B1-embedded pavement models having Soil K01 as subgrade soil compacted at $70 \%$ MDD
Fig. 9 Vertical stress versus per cent strain plots for Treated JGT-embedded pavement models having Soil K01 as subgrade soil compacted at $70 \%$ MDD

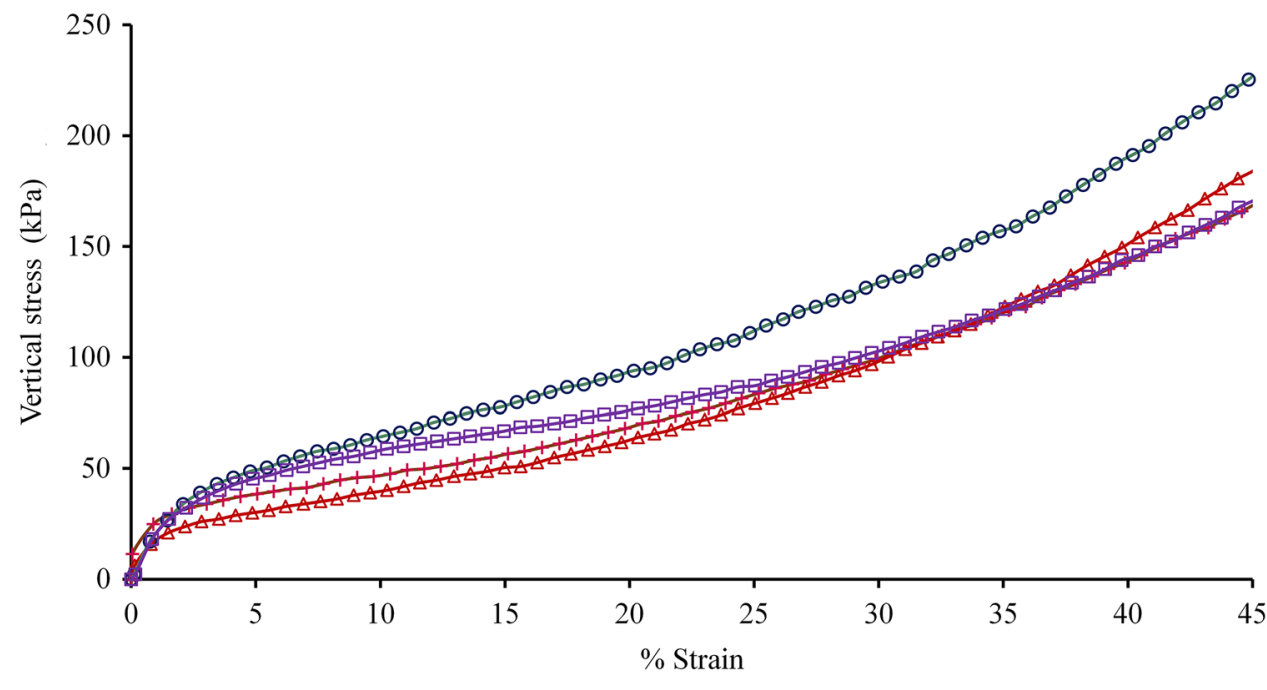

+Soil K01 Blended JGT B1_12 weeks

ASoil K 01 Blended JGT B1 Zero week

@Soil K01_Blended JGT B1_4 weeks

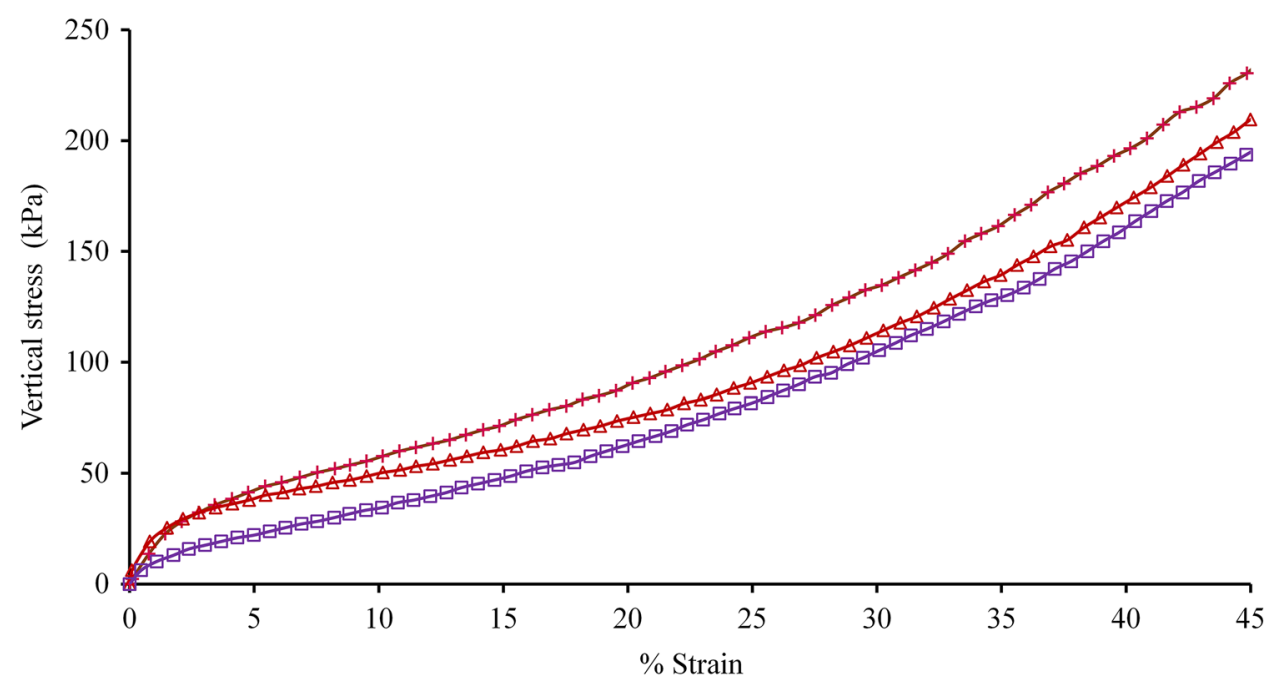

+Soil K01_Treated JGT_12 weeksASoil K01_Treated JGT_Zero weekESoil K01_Treated JGT_4 weeks

up to 24 weeks of curing and also the results of subgradeonly model (zero-week cured) testing, the following can be observed:

(a) Subgrade-only model is showing the lowest stressstrain profile than the control models (Fig. 7) as expected. Stress-strain profiles for 12-week and 24-week treated control models are almost similar which are higher than the zero-week control model but lower than 4-week control model. The subgrade densities of the zero-week, 4-week, 12-week and 24-week control models and subgrade-only model are $15.53 \mathrm{kN} / \mathrm{m}^{3}, 15.76 \mathrm{kN} / \mathrm{m}^{3}, 15.60 \mathrm{kN} / \mathrm{m}^{3}, 15.58$ $\mathrm{kN} / \mathrm{m}^{3}$ and $15.32 \mathrm{kN} / \mathrm{m}^{3}$, respectively. It can be con- cluded from these curves that there is a considerable improvement in the pavement system due to consolidation of subgrade within 12 weeks and no further improvement beyond 12 weeks indicates that consolidation is almost complete by that time. The density of the 4-week model is slightly higher than other control models which may be due to hand compaction and hence yielded highest stress-strain curve.

(b) Tank subgrade densities for the pavement models embedded with Blended JGT B1 cured for zero week, 4 weeks, 12 weeks and 24 weeks are 16.04 $\mathrm{kN} / \mathrm{m}^{3}, 15.77 \mathrm{kN} / \mathrm{m}^{3}, 15.12 \mathrm{kN} / \mathrm{m}^{3}$ and $15.59 \mathrm{kN} / \mathrm{m}^{3}$, respectively. For Blended JGT B1-embedded pavement models, the curves for 12-week and 24-week 
almost merge with each other beyond $30 \%$ strain level. For 12-week and 24-week cured models, residual strengths of the embedded blended JGT fabric become almost similar, i.e. about $90 \%$ in machine direction and $80 \%$ in cross-machine direction, though tank densities differ to some extent, i.e. $15.12 \mathrm{kN} / \mathrm{m}^{3}$ (12-week) and $15.59 \mathrm{kN} / \mathrm{m}^{3}$ (24-week). This occurs due to the fact that the strength contribution from the jute part of the blended JGT becomes around 25\% and $14 \%$ of its initial contribution after remaining embedded inside saturated Soil K01 for 12 weeks and 24 weeks, respectively, as per the biodegradability study [13]. Hence, major strength contribution comes from the polypropylene part which is non-biodegradable.

(c) Tank subgrade density values for the pavement models embedded with Treated JGT are $15.68 \mathrm{kN} / \mathrm{m}^{3}$ (zeroweek cured), $15.07 \mathrm{kN} / \mathrm{m}^{3}$ (4-week cured) and 15.58 $\mathrm{kN} / \mathrm{m}^{3}$ (12-week cured). Referring to Fig. 9, 12-week cured curve shows the highest profile, while those for 4-week and zero-week are in the lowest and intermediate positions, respectively. From biodegradability study of the Treated JGT fabric in Soil K01 [13], it was found that residual strength values for zero-week and 4-week are nearly the same (80-89\%), but those values for 12 -week cured model are only 35\%/31\% (MD/ CD). But, as subgrade soil consolidation has already taken its effect in 12-week model which supersedes the detrimental effect of fabric degradation during 12-week duration, hence, 12-week cured model produced the highest stress-strain profile among the three.

\subsubsection{Static test results for the pavement models having Soil B01 as subgrade soil}

In Fig. 10, vertical stress versus per cent strain plots for subgrade-only and control pavement models consisting of Soil B01 as subgrade are depicted. The control model tanks were subjected to water curing for durations from zero week to 24 weeks, whereas the subgrade-only models were water-cured up to 12 weeks. The following can be observed from these plots:

(a) Curves for the subgrade-only models occupy much lower levels of vertical stresses in comparison with the control ones for the entire strain range of 0 to $45 \%$. The 12 -week treated subgrade-only model has produced the highest stress-strain profile in comparison with the other two subgrade-only models. This indicates that Soil B01 becomes stronger due to substantial consolidation within 12 weeks even without any surcharge loads.

(b) Curves for the control zero-week cured models are gradually increasing though initially show lower vertical stress values in comparison with those obtained from the 4-week and 12-week treated models.

(c) Curve for the control 12-week cured model shows the highest position up to $30 \%$ strain level; thereafter, it falls below the curve for zero week.

(d) Curve for the control 4-week cured model shows the intermediate stress values in comparison with 12 -week and zero-week ones. But it falls below zeroweek curves beyond $24 \%$ strain level.
Fig. 10 Vertical stress versus per cent strain plots for subgrade-only and control pavement models containing Soil B01 as subgrade soil compacted at $100 \%$ MDD

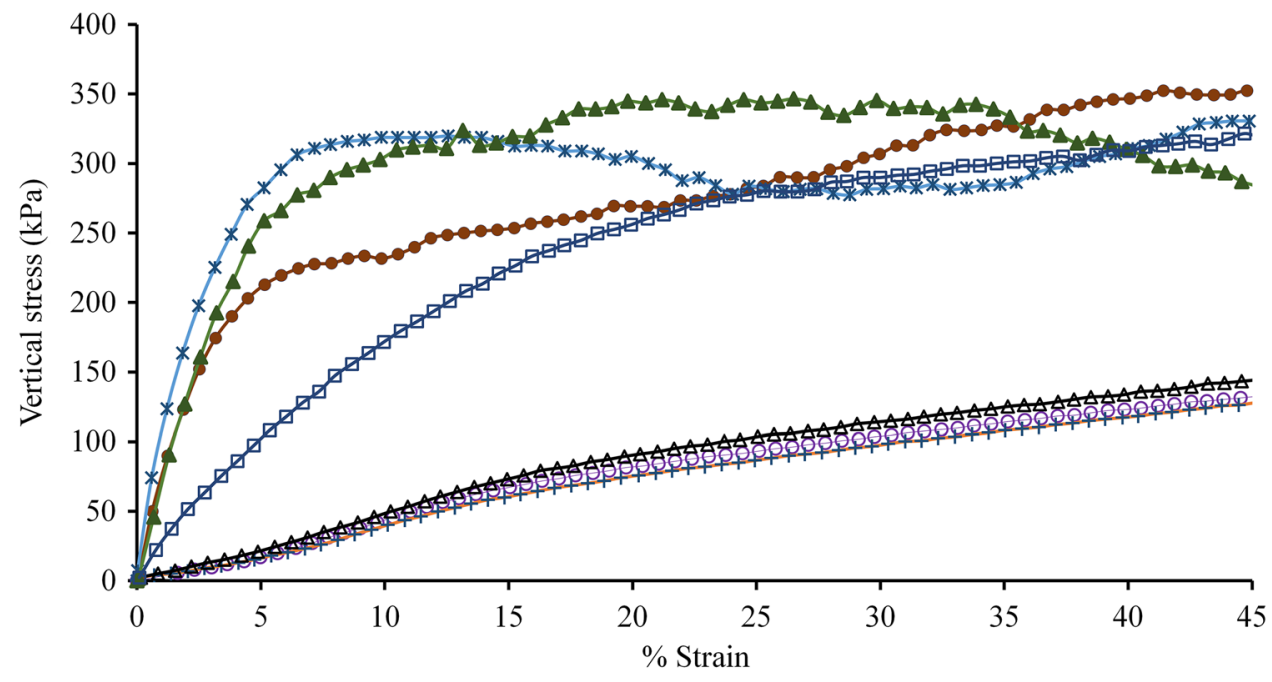

OSoil B01_Only subgrade Zero week ASoil B01_Only subgrade_12 weeks *Soil B01-Control 4 weeks ESoil B01_Control_24 weeks
+Soil B01_Only subgrade_4 weeks -Soil B01_Control_Zero week ASoil B01-Control 12 weeks 
(e) Curve for the 24-week cured control model occupies the lowest position amongst all the control model curves though it gradually increases and crosses the 4-week cured control model curve at $25 \%$ strain level.

It should be mentioned that the subgrade densities are in the same range for all the control models, i.e. $13.0 \mathrm{kN} /$ $\mathrm{m}^{3}$ (zero-week), $13.0 \mathrm{kN} / \mathrm{m}^{3}$ (4-week) and $12.9 \mathrm{kN} / \mathrm{m}^{3}$ (12week) except the 24-week cured control model as it has the lowest density of $12.0 \mathrm{kN} / \mathrm{m}^{3}$. This may be the reason for having the lowest stress-strain profile for the 24-week cured control model.

The following may be observed from Figs. 10 and 11:

(a) There is a significant improvement in stress-strain behaviour in Blended JGT B1-embedded pavement models in comparison with the control models for all the treatment durations up to 24 weeks.

(b) Starting from the initial strain levels, the Blended JGT B1 pavement models are showing higher levels of vertical stresses than the control ones except the 12-week treated models. The 12-week control model has shown slightly better performance than the 12-week reinforced one up to $10 \%$ strain level. But, above this strain level the reinforced model has shown higher stress values than its control counterpart. Due to gradual biodegradation in the jute part of the blended geotextile fabric, there will be little or no contribution from the jute part beyond three or four months practically. So, the entire load will be sustained by the more extensible synthetic part only which starts taking load after getting extended beyond $10 \%$. But there is again improvement in ver- tical stress values for all the strain levels for 24-week treated reinforced model due to the effect of further consolidation of the subgrade.

(c) If comparison is made among the reinforced models for different treatment durations, then the stressstrain profiles are lower for 4-week, 12-week and 24-week cured tanks in comparison with the zeroweek treated tank. This is due to the fact that zeroweek cured tank has the highest subgrade density of $12.89 \mathrm{kN} / \mathrm{m}^{3}$ in comparison with the 4-week $(11.34$ $\left.\mathrm{kN} / \mathrm{m}^{3}\right), 12$-week $\left(12.56 \mathrm{kN} / \mathrm{m}^{3}\right)$ and 24-week (12.83 $\mathrm{kN} / \mathrm{m}^{3}$ ) models.

(d) The biodegradation of Blended JGT B1 for 24-week cured model (residual strengths, MD/CD: 79\%/71\% after being kept embedded in the model pavement in contact with saturated Soil B01 for 175 days and subsequently undergone a static loading test) might have yielded the lower stress values beyond $11 \%$ strain level than that of the zero-week cured model embedded with Blended JGT B1(residual strengths, MD/CD: 96\%/87\% after embedment in model in contact with saturated Soil B01 for 7 days and subjected to a static test).

The following findings can be observed from Figs. 11, 12, and 13:

(a) Zero-week curves for all the pavement models embedded with Blended JGT B1 and Blended JGT B2 are showing higher stress-stain profiles than their 4-week counterparts, while the associated curves with Synthetic GT are nearly similar. Among them, Blended JGT B2 is showing the highest profile. This
Fig. 11 Vertical stress values at different per cent strain levels for Blended JGT B1-embedded pavement models having Soil B01 as subgrade soil compacted at $100 \%$ MDD

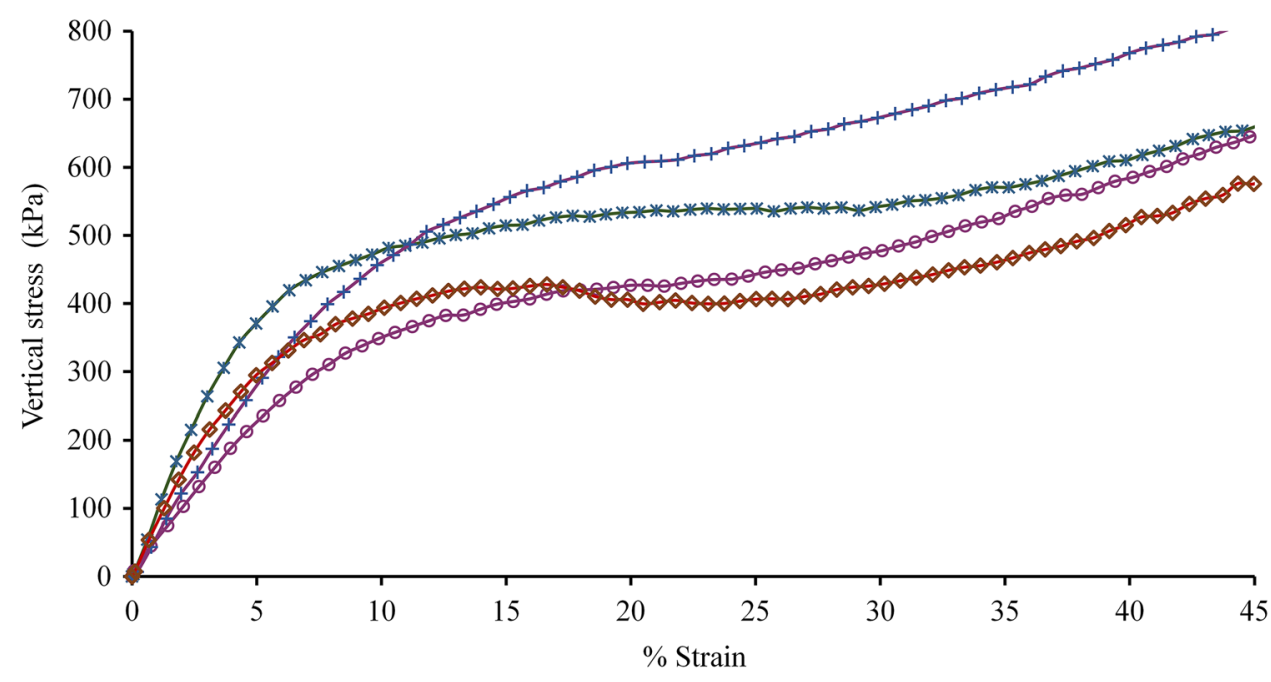

*Soil B01_Blended JGT B1_24 weeks

eSoil B01_Blended JGT B1_12weeks

+Soil B01_Blended JGT B1 Zero week
^Soil B01_Blended JGT B1_4 weeks 
Fig.12 Vertical stress versus per cent strain plots for pavement models embedded with Blended JGT B2 containing Soil B01 as subgrade soil, compacted at $100 \%$ MDD
Fig.13 Vertical stress versus per cent strain plots for pavement models embedded with Synthetic GT containing Soil B01 as subgrade soil, compacted at $100 \%$ MDD

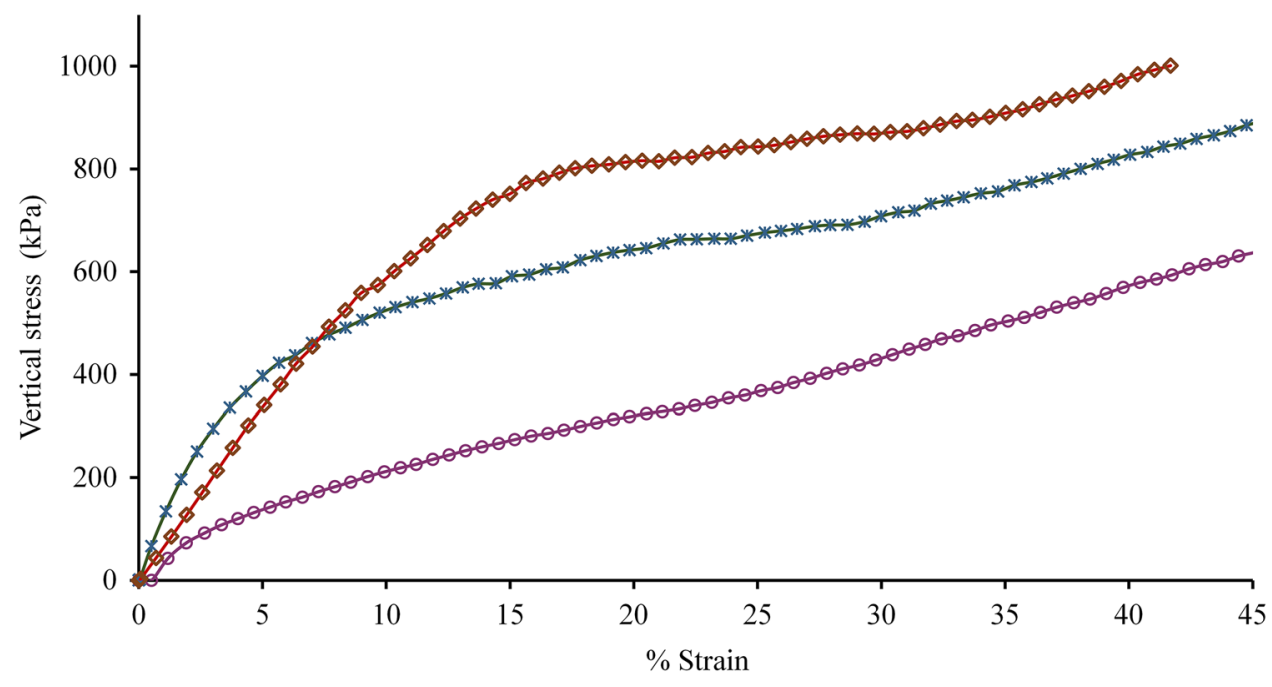

*Soil B01_Blended JGT B2_24 weeks

eSoil B01_Blended JGT B2_4 weeks

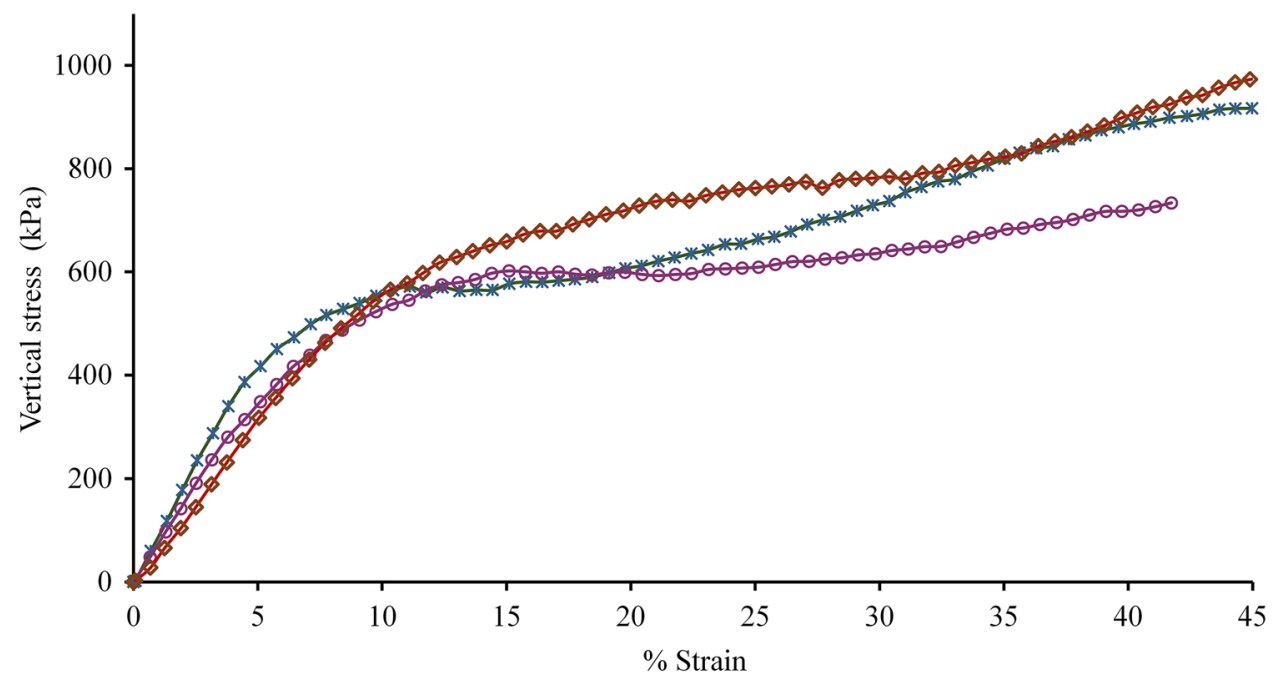

*Soil B01_Synthetic GT_4 weeks eSoil B01_Synthetic GT_12 weeks 2 Soil B01_Synthetic GT_Zero week

is possibly due to the fact that subgrade soil densities for 4-week cured models with the two former geotextiles are considerably lower than those of the zero-week counterparts. Subgrade densities are very close for the two zero-week cured tanks, i.e. $12.89 \mathrm{kN} /$ $\mathrm{m}^{3}$ and $12.95 \mathrm{kN} / \mathrm{m}^{3}$, respectively, vis-à-vis those for 4-week cured tanks, i.e. $11.33 \mathrm{kN} / \mathrm{m}^{3}$ and $12.39 \mathrm{kN} / \mathrm{m}^{3}$, respectively.

(b) For 4-week cured models, pavement model embedded with Synthetic GT is showing the highest position than the other two. This is possibly because the subgrade densities in model tanks for Blended JGT B1and Blended JGT B2-embedded models are $11.33 \mathrm{kN} /$ $\mathrm{m}^{3}$ and $12.39 \mathrm{kN} / \mathrm{m}^{3}$, respectively, vis-à-vis the same for Synthetic GT-embedded model is $13.13 \mathrm{kN} / \mathrm{m}^{3}$.

(c) For the Synthetic GT-embedded models, the stressstrain profiles are gradually declining with curing period though the tank densities are improving from $12.88 \mathrm{kN} / \mathrm{m}^{3}$ to $13.40 \mathrm{kN} / \mathrm{m}^{3}$ in 12 weeks. This may be due to substantial amount of stress relaxation in the synthetic fabric. In spite of extensive biodegradation in the jute part of Blended JGT B2, the 24-week cured model embedded with the same JGT performed better than 12-week cured model embedded with Synthetic GT though the subgrade density of the former is lower $\left(12.73 \mathrm{kN} / \mathrm{m}^{3}\right)$ than the latter $\left(13.40 \mathrm{kN} / \mathrm{m}^{3}\right)$. In general, Blended JGT B2 performed better than 
blended JGT B1 and the experimental synthetic geotextile product. The reason may be reasonably higher strength of Blended JGT B2 than the two latter geotextile products as also reported by the researchers [16].

\section{Summary and conclusions}

To investigate the efficacy of some newly developed JGTs, e.g. rot-proof treated JGT and jute-PP blended JGTs, with different blend proportions and weave construction, in reinforcing low traffic volume pavements, several unpaved pavement models were prepared. The models were constructed in rectangular tanks incorporating any one of the four different JGTs (grey or rot-proof-treated or blended JGTs) or a synthetic geotextile at the interface of a compacted subgrade and a modelled WMM layer. Three widely varying subgrade soils from different geo-climatic regions were employed for the model preparation. To this end, some suitable combinations of subgrade soil and geotextile were chosen for model preparation based on biodegradability behaviour of these JGTs in those saturated soils. Some control and subgrade-only models were also prepared for comparison purpose. Static loading tests were carried out on each of the pavement models after completion of the desired water-curing period according to the experimental plan. Residual tensile strengths of the exhumed JGTs from the model tanks were also determined. The conclusions from these experimental activities are:

1. From all the experiments under this test regime, it is evident that there is a substantial improvement in stress-strain behaviour of the pavement models due to incorporation of any type of the experimental JGTs (may it be grey or rot-proof treated or blended type) over control models for all the treatment time durations up to 24 weeks. So, all types of the experimental JGTs are stabilizing/reinforcing the pavement models built over soft subgrade.

2. There is an immediate improvement in the stressstrain behaviour of the pavement model due to application of any of the JGTs like any other synthetic geotextiles vis-à-vis the time-consuming methods of soil stabilization, e.g. cement or lime stabilization. Hence, JGT provides an advantage of rapid construction of roads at low costs (jute being indigenous in Indian subcontinent).

3. There is an improvement in stress-strain behaviour with curing periods for control tests also. The results of the JGT-embedded tests have shown a significant improvement over the controls, more so at higher strains (which reflects the rutting in a real pavement).

4. Improvement in vertical stress-strain behaviour of the pavement systems is found in spite of biodegradation of the JGTs up to 24 weeks (equivalent to two monsoons). This indicates that substantial consolidation of subgrade has occurred within the watercuring period (within 12-24 weeks). For Kolkata Silty Soil, the consolidation is almost complete within 12 weeks (i.e. 3 months), while that for Black Cotton soil is continuing up to 24 weeks (i.e. 6 months).

5. While comparing the zero-week cured models having same type of subgrade soil layers but compacted at two different subgrade densities, (i.e. models having Soil G01 subgrade compacted at $74 \%$ of MDD and $100 \%$ MDD), efficacy of JGT reinforcement over the control is found more in lower density models than the higher density models. This fact is more prominent at the higher strain levels. This infers that immediate road construction work can be started employing a suitable JGT as 'separator-cum-reinforcement' layer over a soft subgrade. This effect gradually reduces with time as the soil itself becomes stronger due to consolidation and even biodegradation of the JGT does not substantially affect the pavement system within the experimental time domain.

6. For Guwahati Lateritic Red Soil pavement models: improvement in stress-strain behaviour: $53 \%$ to $128 \%$ due to use of Grey JGT and $44 \%$ to $175 \%$ using rot-proof treated JGT over control (considering improvement at 30\% strain level).

7. For Kolkata Alluvial Silty Soil pavement models: improvement in stress-strain behaviour: $39 \%$ to $106 \%$ due to use of Blended JGT B1 and $52 \%$ to $136 \%$ using rot-proof treated JGT over control (considering improvement at 30\% strain level).

8. For Andhra Pradesh Black Cotton Soil pavement models: improvement in stress-strain behaviour: $46 \%$ to $117 \%$ due to use of Blended JGT B1 over control and $49 \%$ to $181 \%$ due to use of Blended JGT B2 over control (considering improvement at $30 \%$ strain level).

9. Blended JGT B2 performed better than Blended JGT B1 and the experimental synthetic geotextile product. But, both the blended JGT products' tensile strengths in cross-machine direction have to be improved keeping the extensibility same or even lowering it to get further enhancement in performance.

10. Synthetic GT-embedded models showed gradually declining vertical stress-strain profiles with curing time. This happened possibly due to considerable 
effect of stress relaxation in the extensible synthetic fabric.

11. The test results overall establish the fact that inclusion of geotextile reinforcement (either any of the experimental JGT or the synthetic geotextile) results in redistributing the applied vertical load to a wider area, thus reducing the stress concentration and achieving an improved vertical stress distribution on top of subgrade layer. This was also observed by other researchers $[3,16,17]$.

Acknowledgements The present research paper is a part of the research and development outcomes of the Ministry of Textiles, Government of India sponsored project, entitled, 'Development of Standards for Use of Jute Geotextiles (JGTs) in Rural Roads' implemented by IJIRA. The authors would like to express their sincere gratitude to Dr. Subrata Gupta, the then Jute Commissioner for initiating the study and to the Ministry of Textiles, Government of India, for funding the project. The authors would like to sincerely thank Dr. U.S. Sarma, Director, IJIRA, and Dr. S. K. Chakrabarti, Deputy Director, IJIRA, for their timely advice. Cooperations and helps extended by Dr. Sandip Bose, Shri Palash Paul, Smt. Soumita Chowdhury, Shri Debi Prasad Gon, Shri Arindam Das and Shri Jayjit Mukherjee of IJIRA are hereby acknowledged for carrying out the present work. Special thanks are due to Shri Ayanjyoti Pal and Shri Supriya Pal for their dedicated experimental contribution.

Funding This work is a part of a research and development project, namely 'Development of Standards for Use of Jute Geotextiles (JGTs) in Rural Roads' which was supported by the Ministry of Textiles, Government of India [Sanction Letter number: Jute(T)-6/259/15-II Dated 18 March 2016]. However, the funder has no role in study design, data collection and analysis, decision to publish or preparation of the manuscript.

\section{Compliance with ethical standards}

Conflict of interest The authors declared no potential conflicts of interest with respect to the research, authorship and/or publication of this article.

\section{References}

1. Road development plan vision: 2021 (2001) Ministry of Road Transport and Highways, Government of India.

2. IRC: SP-72 (2015) Guidelines for the design of flexible pavements for low volume rural roads. The Indian Roads Congress, New Delhi, India

3. Ramaswamy SD, Aziz MA (1989) Jute geotextile for roads. In: Proc International workshops on geotextiles, Vol 1, Central Board of Irrigation and Power, India, pp 259-266
4. Benerjee PK (1996) Development of new geosynthetic products through blends of natural fibres. Proc International seminar \& technomeet on environmental geotechnology with geosynthetics. The Asian Society for Environmental Geotechnology, New Delhi, India, pp 337-346

5. Rao GV, Dutta RK (2006) Coir geotextiles in rural roads. Highway Research Bulletin 74:9-15

6. Batra SK (1998) Other long vegetable fibers. In: Lewin M, Pearce EM (eds) Handbook of fiber chemistry, 2ndedn. Marcel Dekker, New York, pp 505-575

7. Banerjee PK, Ghosh M (2008) Studies on jute-asphalt composites. J Appl Polym Sci 109(5):3165-3172. https://doi. org/10.1002/app.28325

8. Committee on commodity problems (2017) Joint meeting of the thirty ninth session of the intergovernmental group on hard fibres and the forty first session of the intergovernmental group on jute, kenaf and allied fibres. Tanga, United Republic of Tanzania, 15-17 November 2017. https://www.fao.org/fileadmin/ templates/est/COMM_MARKETS_MONITORING/Jute_Hard_ Fibres/Documents/IGG_39/17-4-JuteIndia.pdf

9. Som N, Sahu RB (2003) Jute geotextile in road and structural foundations. In: Anthology of technical papers on Applications of Jute Geotextile and Innovative Jute Products, Jute Manufactures Development Council, India, pp 17-34

10. Ghosh M (2006) Development of jute-based asphalt overlay fabric. PhD thesis, Indian Institute of Technology Delhi, India.

11. Ghosh M, Banerjee PK, Rao GV (2010) Development of asphalt overlay fabric from jute. J Text Inst 101:431-442. https://doi. org/10.1080/00405000802461310

12. Sahu RB, Hajra HK, Som N (2004) A laboratory study on geojute reinforced soil bed under cyclic loading. In: Proc Indian geotechnical conference 2004: ground engineering emerging techniques (GREET), Indian Geotechnical Society, Warangal Chapter, India, pp 449-452

13. Ghosh M, Rao GV, Chakrabarti SK, Pal S, Sarma US (2019) Biodegradability study to develop longer life jute geotextiles for road applications. Text Res J 89(19-20):4162-4172. https://doi. org/10.1177/0040517519828985

14. IRC: 109 (1997) Guidelines for Wet Mix Macadam. The Indian Roads Congress, New Delhi, India. https://thelibraryofcivileng ineer.files.wordpress.com/2015/09/irc-109-1997-guidelines-forwet-mix-macadam.pdf

15. Pancar EB, Akpınar MV (2016) Comparison of effects of using geosynthetics and lime stabilization to increase bearing capacity of unpaved road subgrade. Adv Mat Sci Eng. https://doi. org/10.1155/2016/7129356

16. Rao GV, Dutta R (2004) Coir products in ground improvement. In: Proceedings of Indian geotechnical conference 2004: ground engineering emerging techniques (GREET), Indian Geotechnical Society, Warangal Chapter, India, pp 440-443

17. Abu-Farsakh M, Hanandeh S, Mohammad L, Chen Q (2016) Performance of geosynthetic reinforced/stabilized paved roads built over soft soil under cyclic plate loads. Geotext Geomembr 44(6):845-853

Publisher's Note Springer Nature remains neutral with regard to jurisdictional claims in published maps and institutional affiliations. 